Agrotrópica 32(2): 147 - 156. 2020.

Centro de Pesquisas do Cacau, Ilhéus, Bahia, Brasil

\title{
EFEITO DO REVESTIMENTO A BASE DE QUITOSANA NO ALHO IN NATURA
}

\author{
Nádia Ligianara Dewes Nyari*, Mathilde Agnès Liliane Noel, Olivia Caroline Catherin \\ Maillard, Quentin Louis-Joseph Aubert, Vincent Alain Jean Hardy, Aline Ghiotti, Geverson \\ Tobias Bohm, Sandra Ines Horn Bohm
}

\author{
Centro Universitário UniLaSalle, Lucas do Rio Verde - MT, Av. Universitária, 1000, Parque das Emas - Lucas do Rio Verde \\ MT, 78455-000, Brasil.*nadia.nyari@unilasallelucas.edu.br
}

\begin{abstract}
Alho possui uma vida de prateleira extremamente curta, principalmente quando se retira a casca, que serve como barreira aos agentes externos favorecendo assim, ao aparecimento de agentes nocivos, contribuindo para a deterioração de forma mais rápida do alimento. Nesse sentido o objetivo desse estudo visa avaliar a potencialidade da quitosana como barreira de recobrimento comestível do alho in natura pós-colheita a fim de integrar a Agricultura familiar no desenvolvimento local e regional. Sendo avaliados as propriedades físico-químicas, tais como: massa, murchamento, umidade, cinzas, sólidos totais, matéria seca, acidez titulável, $\mathrm{pH}$, proteína, lipídios, fibra bruta e índice industrial. Os resultados mostraram não haver diferença significativa $(\mathrm{p}<0,05)$ entre os tratamentos. Observamos valores significativos de perda de massa da amostra com quitosana (QU) em média de $40 \%$ enquanto que a amostra padrão foi de $60 \%$, sendo assim o revestimento teve o papel importante de proteção e de barreira física, diminuindo as trocas gasosas e perda de vapor d'água. Para a percentagem de bulbilhos chochos, $\mathrm{pH}$, proteína, a umidade seguiu a mesma tendência, desempenhado um papel de manutenção das atividades enzimáticas, prolongando a vida útil e auxiliando a agricultura sustentável. Dentro do conceito da tecnologia de recobrimentos comestíveis e o uso da Quitosana ser ainda pouco explorada, especialmente usando como matéria prima alho in natura, possibilitou perceber o aumento significativo das propriedades físico química de tais produtos.
\end{abstract}

Palavras-chave: Quitosana, Allium sativum L, vida de prateleira, tecnologia, recobrimento.

Effect of chitosan based coating on garlic in natura. Garlic has an extremely short shelf life, especially when the peel is removed, which serves as a barrier to external agents, thus favoring the appearance of harmful agents, contributing to the faster deterioration of the food. In this sense, the objective of this study aims to evaluate the potential of chitosan as a barrier for edible coating of fresh garlic after harvest in order to integrate family farming in local and regional development. The physico-chemical properties are evaluated, such as: mass, wilt, humidity, ash, total solids, dry matter, titratable acidity, $\mathrm{pH}$, protein, lipids, crude fiber and industrial index. The results showed that there was no significant difference $(\mathrm{p}<0.05)$ between treatments. We observed significant values of mass loss of the sample with chitosan (QU) on average of $40 \%$ while the standard sample was of $60 \%$, thus the coating had an important role of protection and physical barrier, reducing gas exchange and loss of water vapor. For the percentage of cut bulbils, $\mathrm{pH}$, protein, moisture followed the same trend, playing a role in maintaining enzymatic activities, extending their useful life and helping sustainable agriculture. Within the concept of edible coatings technology and the use of Chitosan is still little explored, especially using raw raw garlic, it was possible to notice the significant increase in the physical and chemical properties of such products.

Key words: Chitosan, Allium sativum $L$, shelf life, technology, coating. 


\section{Introdução}

Após serem colhidas, a maioria dos vegetais como o alho apresentam grande aceleração no seu processo de deterioração e degradação, sobretudo devido as grandes mudanças bioquímicas e fisiológicas que ocorrem, especialmente em decorrência dos procedimentos inadequadas de manuseio e de acondicionamento. Segundo a Associação Nacional dos Produtores de Alho (Anapa, 2018), da Companhia Nacional de Abastecimento (Conab, 2018) e da Empresa Brasileira de Pesquisa Agropecuária (Embrapa, 2018) o alho na sua forma in natura possui alta perecibilidade e vida pós-colheita muito curta, fazendo com que sejamos desafiados a apresentar alternativas de mercado a fim de aumentar a vida útil desse produto (Prati et al., 2010).

De acordo com Bessa et al. (2017) o alho é considerado um dos principais condimentos utilizados na culinária brasileira e em outros países, se destaca por possuir características excepcionais de sabor, além de compostos organosulfurados, responsáveis pela pungência e aroma característico.

A conservação pós-colheita usualmente empregada está, em quase sua totalidade, centrada na cadeia de frio e nas boas práticas de armazenamento. Todavia, uma alternativa que está sendo cada vez mais avaliada e divulgada é quanto ao aumento no tempo de conservação, entretanto os procedimentos adequados como o emprego de coberturas comestíveis permitem maior flexibilidade de manuseio e comercialização, minimizando assim os danos.

Entre as matérias-primas empregadas na produção de coberturas comestíveis destaca-se a quitosana (QU), que trata-se de um polímero biodegradável, natural e biocompatível a base de quitina, polissacarídeo de alta massa molecular, comestível e não tóxico. Possui atividade antimicrobiana baixa, fungicida e de grande versatilidade, com capacidade de reduzir trocas gasosas com o ambiente, faz com que seja inibido eventos metabólicos que os prejudicam (De Araújo e Shirai, 2017), além disso, não apresentaram alterações nas características físicas e químicas durante o processo de armazenamento (Tavares et al., 2017).

Segundo De Araújo e Shirai (2017) esses revestimentos não têm como objetivo substituir o uso dos materiais convencionais de embalagens ou mesmo eliminar definitivamente o emprego de técnicas já utilizadas, mas sim o de apresentar uma atuação funcional e coadjuvante, contribuindo para a preservação da textura e do valor nutricional, reduzindo a perda ou ganho excessivo de água.

De acordo com a literatura esses compostos podem ser usados especialmente na conservação de outros vegetais, como: brócolis (De Araújo e Shirai, 2017), pêra (Almeida, Deziderio \& Maldonado, 2018), tomate (Costa et al., 2012), cenoura (Durango, Soares \& Andrade, 2006), mandioquinha-salsa (Buso et al., 2014), aspargos (Qiu et al., 2013) e alho (Botrel et al., 2007) e frutos como: pêssegos (Santos et al., 2008), mangas (Souza et al., 2011), uva 'Itália' (Camili et al., 2007), uva cv. Sweet Globe® (Félix et al., 2018), polpa de mamão (Lorevice, Moura e Mattoso, 2014), maças Royal gala (Jorge et al., 2011), goiaba (Melo, 2015), mangabas (Nasser et al., 2016), umbu (Granja e Da Cunha, 2018), carambola (Guimarães Sanches, 2018), laranjas (Silva et al., 2017), entre outras. Nesse sentido o objetivo desse estudo visa avaliar a potencialidade da quitosana como barreira de recobrimento do alho in natura pós-colheita, identificando as propriedades físico-químicas a fim de integrar a Agricultura Familiar no desenvolvimento local e regional.

\section{Material e Métodos}

Os experimentos foram conduzidos nos laboratórios de físico-química da Faculdade LaSalle, localizada na cidade de Lucas do Rio Verde, MT, localizado na mesorregião do Norte Mato-Grossense, Brasil. $\mathrm{O}$ alho (Allium sativum) in natura foi adquirido por meio de doação por uma empresa local, onde foram selecionados e sanitizados com solução de cloro ativo (100 $\mathrm{mg} \times \mathrm{L}^{-1} / 3 \mathrm{~min}$ ), em seguida foram drenados e levados para secar em ambiente arejado, com ventilação constante e temperatura de 20 a $30^{\circ} \mathrm{C}$. Posteriormente foram descascados e utilizados no processo em triplicata de amostra e de análise.

A amostra padrão refere-se a amostra sem revestimento, chamada de controle, que servirá de base para comparação das amostras com revestimento. O revestimento usado nesse estudo foi a quitosana, sendo 
preparado conforme as concentrações (1\%, $2 \%$ e $3 \%)$ em água destilada a $70^{\circ} \mathrm{C}$ sob agitação constante por $30 \mathrm{mim}$, em seguida foi deixado em repouso por 24 horas em temperatura ambiente $\left(25\right.$ a $\left.35^{\circ} \mathrm{C}\right)$ para que o resfriamento e decantação. Posteriormente foi realizada a filtragem e a imersão das amostras nas respectivas concentrações por 2 horas, em seguidas foram levadas à secagem por 24 horas e armazenadas em potes de vidros tampados sem luminosidade.

\section{Análises Físicas Químicas}

As análises físicas são descritas segundo a Association of Official Agricultural Chemists (AOAC, 1970, 1990, 2011), Association of Official Analytical Chemistry (AOAC, 2000, 2011), Instituto Adolfo Lutz (IAL, 2018), a Agência Nacional de Vigilância Sanitária (ANVISA, 2005, 2010, 2015, 2018), (De Carvalho et al., 1991; Bessa, 2016).
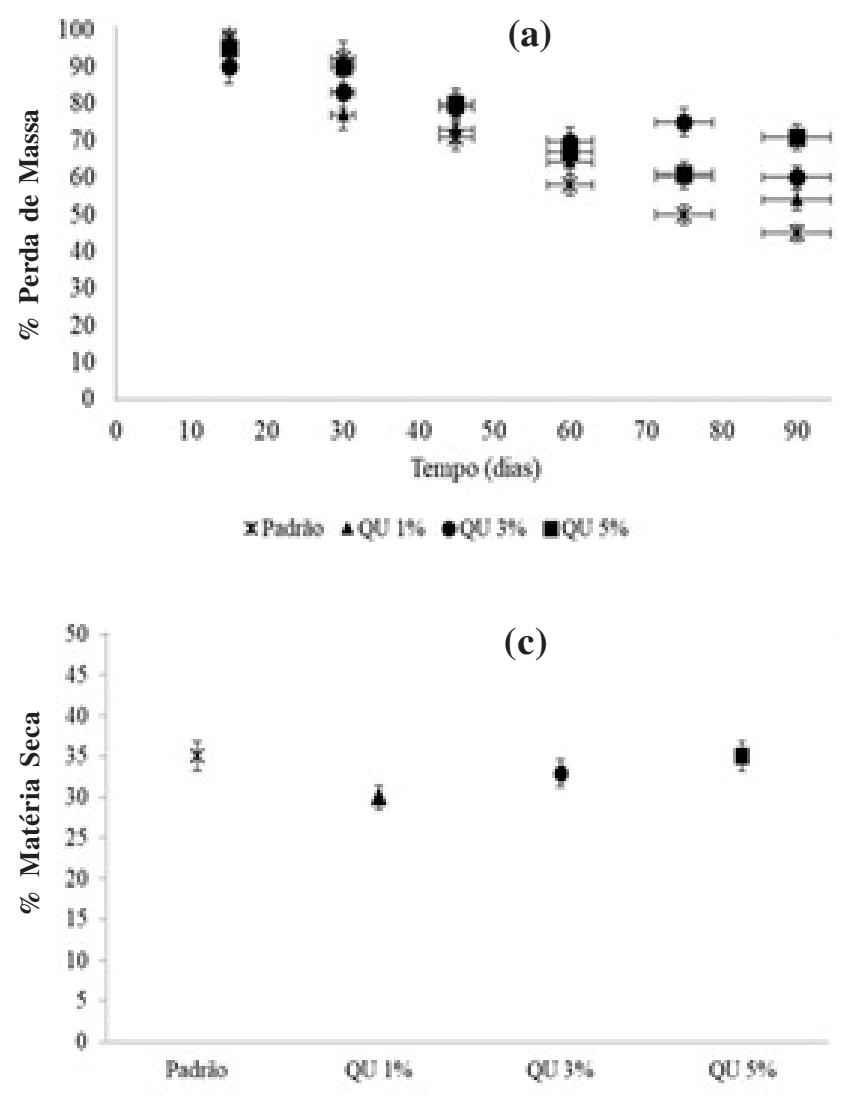

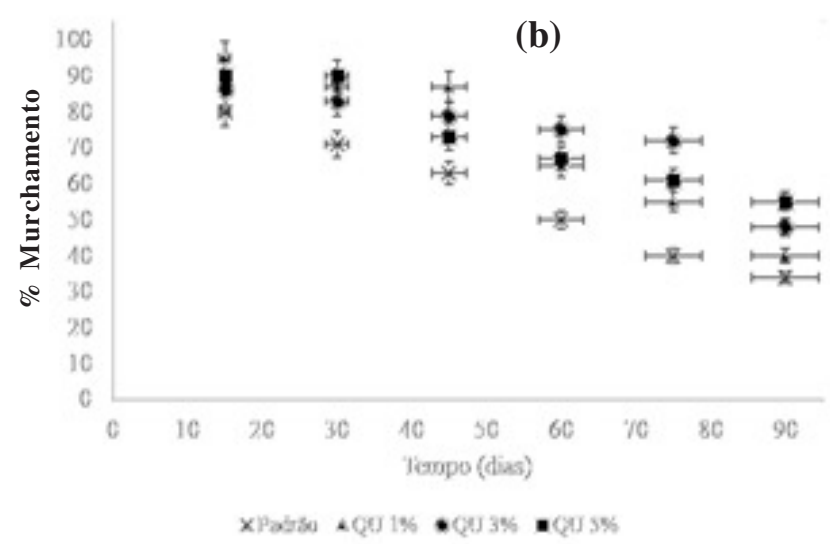

Segundo Bessa et al. (2017) as análises físicoquímicas do alho podem indicar se o produto é mais apropriado ao consumo in natura ou para a indústria, maior capacidade de armazenamento pós-colheita (Chitarra e Chitarra, 2005). As variáveis como o Potencial Hidrogeniônico (determinação de pH), Massa, Murchamento, Cinzas, Sólidos Totais, Matéria Seca, Acidez Titulável, Proteína, Lipídeos e Índice Industrial, dentre outros. Sendo estes extremamente importantes para determinação da qualidade do alho.

\section{Resultados e Discussão}

A Figura 1 apresenta a perda de massa (a), murchamento (b), matéria seca (c) e o teor de sólidos totais (d) das amostras padrão e revestidas com quitosana QU $(1 \%, 3 \%$ e $5 \%)$.

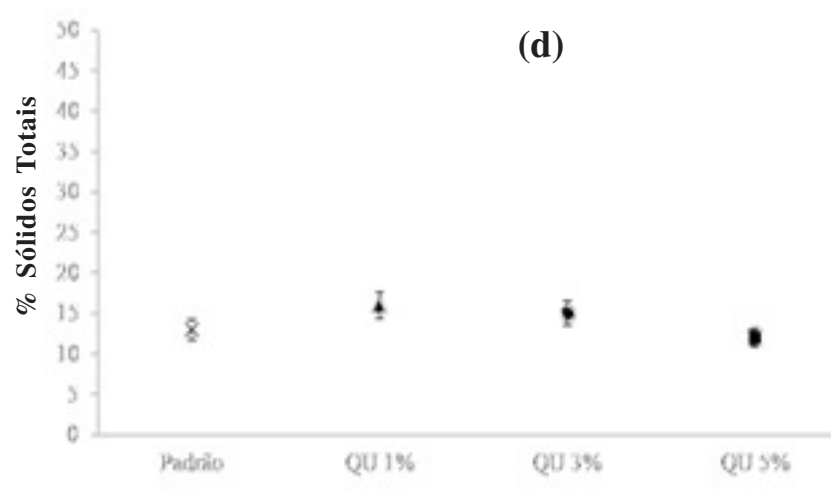

Figura 1. Análise da perda de massa (a), murchamento (b), matéria seca (c) e o teor de sólidos totais (d) referentes às amostras padrão e revestidas com quitosana QU (1\%, 3\% e 5\%). 
A amostra padrão apresentou maior perda de massa com $65 \%$ com relação a massa inicial, a amostra revestida com QU (5\%) foi a amostra que perdeu menor massa, sendo $>30 \%$, seguida da amostra QU (3\%) com $45 \%$ e QU (1\%) $56 \%$ durante os 90 dias de armazenamento. Segundo Henrique, Cereda e Sarmento (2008) os revestimentos podem formar uma barreira física, diminuindo as trocas gasosas e perda de vapor d'água, modificando assim a atmosfera e retardando a senescência, além de dificultar a transferência de umidade e formação de processos de oxidação (Ayranci \& Tunc, 2003).

As maiores variações com relação ao murchamento foram observados na amostra padrão (sem revestimento) com perda $<65 \%$, enquanto para as amostras revestidas com QU a média de murchamento foi de 50\%, independente da concentração $(1 \%, 3 \%$ ou $5 \%)$. O murchamento pode estar sendo favorecido pelo aumento na taxa de desintegração da membrana celular, causando assim perda no conteúdo e consequentemente diminuição na suculência, trazendo alterações morfológicas importantes que podem afetar a cor e a textura (Ayranci $\&$ Tunc, 2003).

A amostra padrão (sem revestimento) obteve maior perda na matéria seca, $35 \%$, enquanto as amostras com revestimento obtiveram uma porcentagem menor, usando o revestimento de QU (1\%) obteve 30\%, QU (3\%) 33\% e QU (5\%) 35\%. O revestimento pode proporcionar aumento do teor de matéria seca devido ao caráter hidrofílico da quitosana que possui baixa solubilidade em água. Esse fato pode ser explicado devido a quitosana em alta porcentagem provocar uma diminuição na perda de água, o que dificulta a transpiração celular que ocorre no interior dos tecidos durante o armazenamento (Chitarra e Chitarra, 2005).

Esses revestimentos a base de quitosana podem ser definidos como uma camada contínua fina depositada na parte superior do produto, fazendo o papel de barreira e protegendo o alimento a possíveis agentes externos que poderiam provocar danos, aumentando assim a vida de prateleira, inibindo o escurecimento enzimático e mantendo as características originais do alimento.

De acordo com Bessa et al., (2017) o murchamento ou a percentagem de bulbilhos chochos estão entre os defeitos mais graves apontados pelas portarias ministeriais, sendo tolerável apenas $15 \%$ para que o lote seja considerado do tipo comercial. Segundo Souza et al., (2011) os efeitos positivos da quitosana estão relacionados às reações de defesa do alimento, favorecendo a produção de glucano-hidrolases que são responsáveis pelo amaciamento e a síntese de fitoalexinas que são compostos fenólicos que reduzem a atividade das enzimas poligalacturonases e pectinametilesterases.

Botrel et al. (2007) ressalta que os bulbilhos de alho possuem uma embalagem natural, chamada de casca, que serve como um barreira natural, que tem a função de regular o transporte de oxigênio e dióxido de carbono, reduzindo assim a perda de umidade, prolongando o sabor e odor do alimento. Mas quando estes passam por um processo de descascamento estão expostos não apenas a alteração nas concentração de oxigênio e dióxido de carbono, mas também o aparecimento e crescimento de agentes patógenos ou antimicrobianas, como fungos filamentosos e leveduras, afetando diretamente a vida de prateleira (De Araújo e Shirai, 2017).

Para o teor de sólidos totais a variável foi de $13 \%$ para a amostra padrão, de $16 \%$ para a amostra revestida com QU (1\%), 14\% para o revestimento com QU (3\%) de $12 \%$ para o QU (5\%). No entanto, houve incremento do teor de sólidos totais independentemente da porcentagem de diluição do revestimento, verificando que as amostra que mais se destacaram, com maiores valores apresentando menores teores de sólidos totais foram no tratamento de quitosana a 5\%, Essa redução nos sólidos pode ser devido à respiração natural que ocorre em vegetais em geral, na qual utilizam a glicose disponível como substrato, para a produção de energia necessária a manutenção dos processos vitais após o desligamento da planta mãe (Costa et al., 2012).

Para Schwimmer \& Weston (1961) e Lopes et al. (2016) destaca que apesar de não haver uma relação direta, o alho quando apresenta teores de sólidos totais significativos, tem boas perspectivas para o processo de industrialização, reduzindo sensivelmente os custos de produção (Costa et al., 2012; Bessa et al., 2017). Chitarra e Chitarra (2005) revestimento a base de quitosana possui grande potencial de cobertura ou de proteção vegetal, a fim de auxiliar da agricultura de forma sustentável (Souza et al., 2011). Na Figura 2 podemos observar os resultados referentes ao teor de 

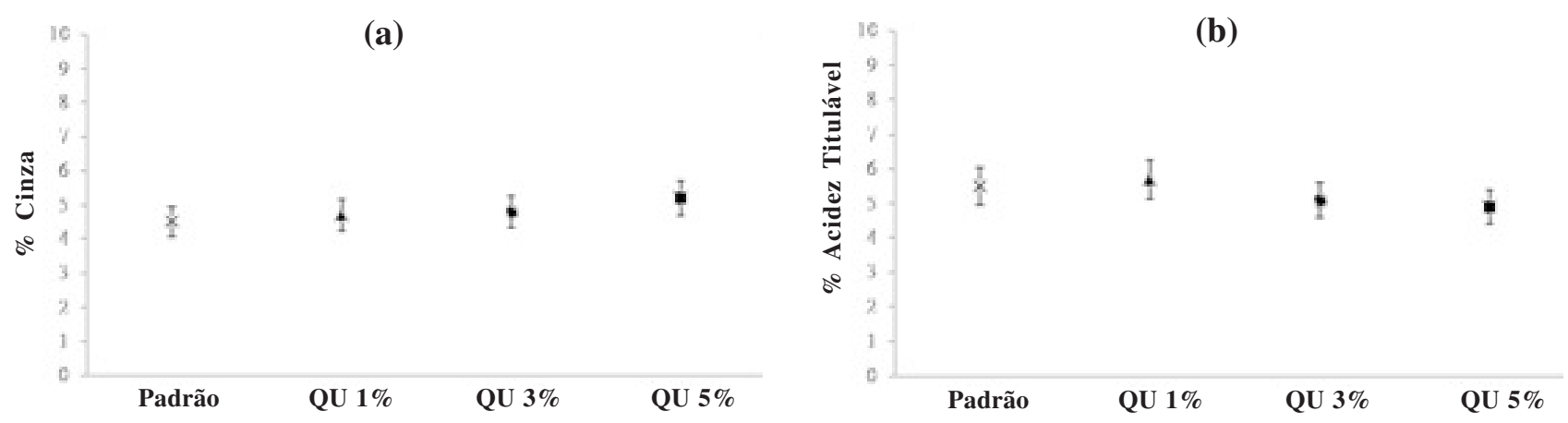

(c)
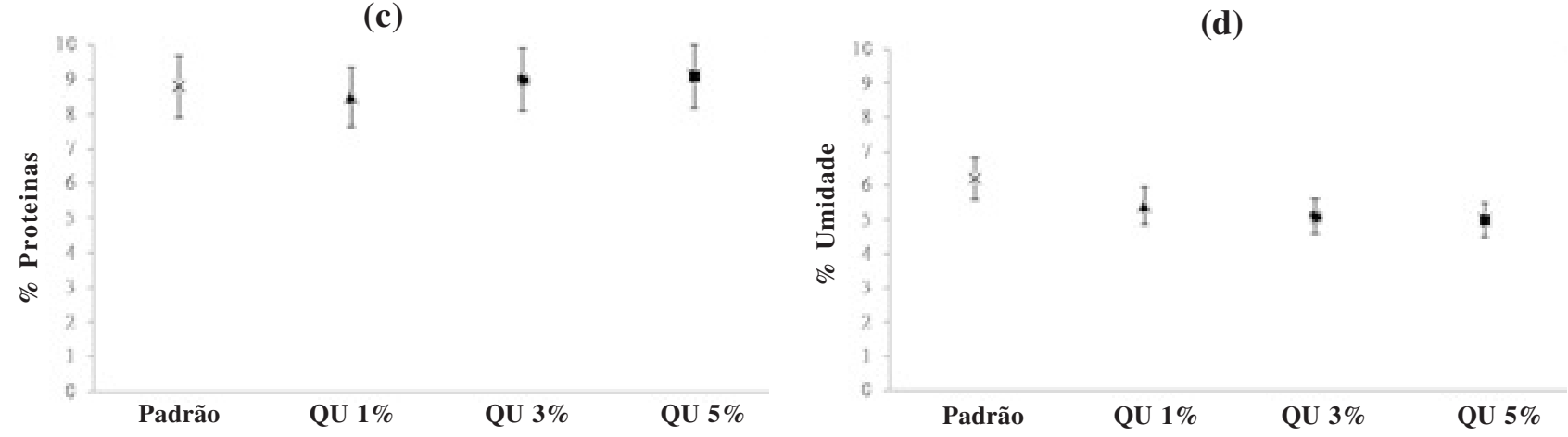

Figura 2. Análise de cinzas (a), acidez titulável (b), proteína (c) e umidade (d) das amostras padrão e revestidas com quitosana QU $(1 \%, 3 \%$ e $5 \%)$.

proteínas (a), umidade (b), cinzas (c) e acidez titulável (d) das amostras padrão e revestidas com quitosana QU $(1 \%, 3 \%$ e $5 \%)$.

$\mathrm{O}$ teor de proteína não variou entre as amostras, ficando com valores representativos entre 8,5 a $9,7 \%$ nas amostras padrão e com revestimento de QU, os valores mais significativos foram observados pela amostra revestida com QU (5\%), esse fato pode ser decorrente pela alta transparência de amidos nativos e modificados (Henrique, Cereda e Sarmento, 2008). O teor de cinzas está relacionado com os percentuais de minerais como potássio, ferro, cálcio, fósforo, magnésio, enxofre e sódio na amostra.

Para a avaliação da umidade a variação foi similar em todas as amostras, sendo superiores a 5\% para as amostras revestidas com QU, onde na diluição à $5 \%$ foi de 5,6\%. Esse parâmetro auxilia a proliferação e atuação de microrganismos, promovendo assim a redução do sabor, odor e tempo ou vida útil do alimento (Alves, et al., 2011). Para a análise de cinzas para as amostras padrão e com revestimento QU (5, 3 e 1\%), se mantiveram superior a 5\%. Estando na média segundo tabela brasileira de composição de alimentos, que descreve que o alho cru possui $4,0 \%$ de cinzas (Lima et al., 2006).

A acidificação variou entre as amostras, onde a padrão (sem revestimento) foi de 5,6\% e para as amostras com revestimento foi proporcional variando entre 5,0 a 6,0\%, independente da diluição de quitosana usada nos ensaios. Chitarra e Chitarra (2005) destaca que as perdas de massa da ordem de 3 a $6 \%$ são suficientes para causar um marcante declínio na qualidade de comercialização. Botrel e Oliveira (2012) afirmaram que o teor de sólidos totais e umidade pode variar de 5 a mais de $20 \%$, na qual, apresentam melhor capacidade de conservação póscolheita e maior potencial de armazenamento, permitindo que os tipos de cultivar satisfaçam às exigências pré estabelecidas pela indústria.

Botrel et al. (2007) destacaram que nos últimos anos, o consumidor tem aumentado a demanda por alimentos seguros e estão especialmente, preocupados com os efeitos colaterais de vários aditivos artificiais 
que estão sendo usados na manutenção da qualidade dos alimentos, principalmente, por serem responsáveis pela inibição e o crescimento de vários microrganismos deterioradores e patogênicos.

De acordo com Souza et al. (2011) os tratamentos com quitosana desaceleraram o processo normal de amadurecimento, diminuindo o teor de acidez, que está associada ao consumo de ácidos no processo respiratório, aumentando o $\mathrm{pH}$ e reduzindo a qualidade sensorial. As coberturas elaboradas a partir de polissacarídeos, como é o usado em nosso estudo, são sensíveis à umidade e apresentam alta permeabilidade ao vapor de água (Souza et al., 2011; Costa et al., 2012). A Figura 3 mostra os resultados quanto ao potencial hidrogeniônico (a), teor de fibra bruta (b), de lipídeos através do extrato estéreo (c) e índice industrial (d) das amostras padrão e revestidas quitosana QU $(1 \%, 3 \%$ e $5 \%)$.

Com relação ao $\mathrm{pH}$ obteve-se variação de em média de 5,0 a 5,7 para as amostras com revestimento e de 4,7 para a amostra padrão sem revestimento.
Segundo Bessa et al. (2017) o pH é um indicativo de sabor de uma hortaliça, tendo relação inversa à acidez. Para De Araújo e Shiral (2017) os valores elevados de $\mathrm{pH}$ podem estar associados com a utilização de ácidos orgânicos em excesso como substrato respiratório, impedindo a difusão de oxigênio.

Para determinação de fibra bruta podemos avaliar que a média para todas as amostras foi de 2,1 a $3 \%$, para a amostra padrão de $2,3 \%$ e com revestimento de QU $(1 \%)$ de $2 \%$, QU (3\%) de 2,5\% e QU (1\%) de 3\%, para o extrato etéreo (lipídeos) as amostras apresentaram valores em torno de 0,87 a $1 \%$. Para Fai, Stamford e Stamford (2008) destaca o potencial biotecnológico de quitosana em sistemas de conservação de alimentos torna-se promissora, com grande potencial e agente conservante natural, impedindo reações químicas e enzimáticas de degradação.

Para a avaliação do índice industrial variou entre 0,7 a $0,8 \%$ para todas as amostras avaliadas. Para De Medeiros et al. (2014) a conservação de alimentos empregando a quitosana prolonga a vida pós-colheita,
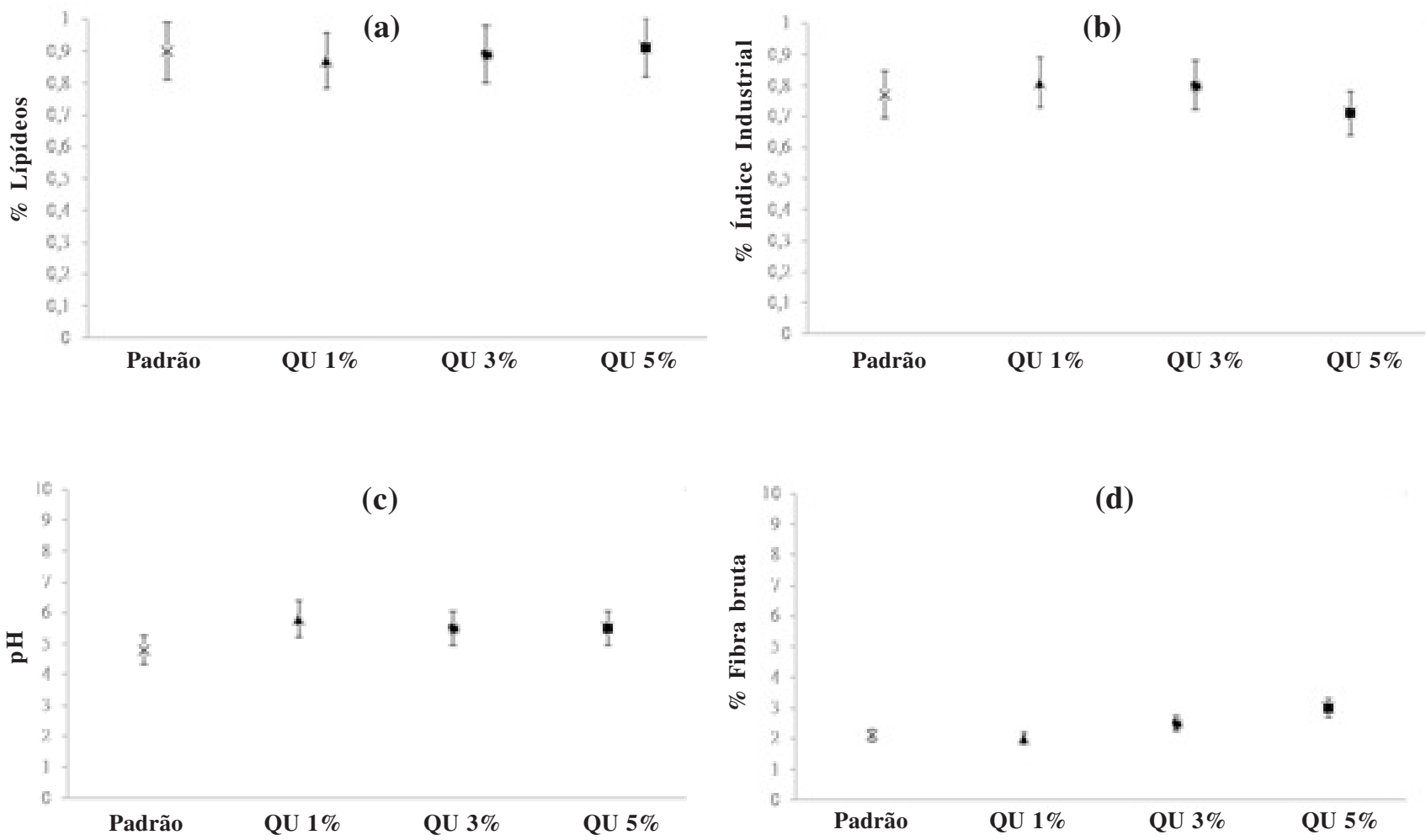

Figura 3. Análise de lipídeos (a), índice industrial (b), potencial hidrogeniônico (determinação de pH) (c) e fibra bruta (d) das amostras padrão e revestidas com quitosana QU (1\%,3\% e 5\%). 
protegendo o produto contra danos físicos e de contaminação. No entanto Lopes et al. (2016) destacaram que apesar de não haver uma relação direta entre os elevados teores de sólidos totais, acidez e índice industrial pode haver influência indireta, ou seja, deve ser realizado estudos mais profundos sobre o assunto. A preservação da qualidade dos alimentos tem se intensificado nos últimos anos, especialmente em laboratórios acadêmicos e governamentais, e também na indústria (Botrel et al., 2007), contribuindo para demanda do consumidor por alimentos de alta qualidade, preocupações ambientais e oportunidades de criar alternativas de mercado para produção de filmes comestíveis de fontes renováveis (Schwimmer \& Weston, 1961).

\section{Considerações Finais}

Podemos identificar através dos resultados obtidos nesse estudo que o alho in natura é uma hortaliça que possui uma vida útil pós-colheita, extremamente curta quando compararmos com outras da mesma espécie, no entanto os revestimentos, especialmente a quitosana vem como alternativa viável de revestimento comestível a fim de diminuir a deterioração e aumentar a vida de prateleira desse produto e integrar a Agricultura Familiar de forma sustentável no desenvolvimento local e regional.

Esse estudo avaliou as propriedades físico-químicas que afetam diretamente a funcionalidade das amostras estudadas com e sem revestimento. Obtendo valores significativos com relação a perda de massa, a amostra padrão apresentou uma redução de $65 \%$ com relação a inicial, enquanto que a amostra revestida com quitosana (QU) foi em torno de $40 \%$, observando que o revestimento foi eficaz e tornando-se uma barreira física, diminuindo as trocas gasosas e perda de vapor d'água. O murchamento ou a percentagem de bulbilhos chochos seguiu a mesma tendência, onde a amostra padrão apresentou uma perda $65 \%$ e a amostra revestida foi de $50 \%$, mostrando que o revestimento pode desempenhar um papel de defesa com relação a manutenção das atividades enzimáticas e reduzindo a perda de sabor e odor do produto.

O teor de matéria seca da amostra padrão foi de $35 \%$ enquanto que a amostra revestida foi em torno de $30 \%$, mostrando que revestimentos a base de quitosana pode ter proporcionado uma barreira a agentes externos, protegendo o alimento e tornando-o viável economicamente. Para o teor de sólidos totais a variável foi de $13 \%$ para a amostra padrão e de $15 \%$ para as amostras revestidas, mostrando que os teores de sólidos estão relacionados com o sabor mais característico da amostra, prolongando a vida útil e auxiliando a agricultura sustentável.

O teor de proteína a umidade não variou entre as amostras, referindo-se a quantidades significativas de minerais como potássio, ferro, cálcio, fósforo, magnésio, enxofre e sódio da amostra, enquanto a umidade menciona-se a capacidade de conservação pós-colheita, além do elevado potencial de armazenamento. Para as análise de cinzas e a acidificação para as amostras padrão e com revestimento mantiveram-se superior a $5 \%$, essa característica está atribuída principalmente aos ácidos orgânicos, que contribuiram para o aroma característico, apresentando componentes voláteis e compostos fenólicos, para a acidez e adstringência da amostra.

Com relação ao $\mathrm{pH}$ obteve-se variação de em média de 5,0 a 5,7 para as amostras com revestimento e de 4,7 para a amostra padrão, pois o $\mathrm{pH}$ é um indicativo de sabor de uma hortaliça e as amostras padrão e com revestimento apresentaram valores em torno de 0,87 a $1 \%$ de extrato estéreo (lipídeos). Sendo assim, o estudo mostrou que o emprego de revestimentos em hortaliças é viável e capaz de preservar por períodos maiores quando comparados a amostra sem revestimento, além de uma tecnologia de grande potencialidade, a fim de aumentar a segurança alimentar e prolongar a vida útil dos alimentos de forma geral.

\section{Literatura Citada}

ALMEIDA, J. C.; DEZIDERIO, M. A.; MALDONADO, R. R. 2018. Aplicação de Biofilme Comestível a base de Quitosana e Dextrina em peras armazenadas sob refrigeração. Foco: Caderno de Estudos e Pesquisas 12:55-72.

ALVES, A. I. et al. 2011. Qualidade de morangos envolvidos com revestimento comestível 
antimicrobiano à base de diferentes fontes de amido. Revista Enciclopédia Biosfera 7:1519-1526.

ASSOCIAÇÃO NACIONAL DOS PRODUTORES DE ALHO - ANAPA. 2018. Disponível em www.anapa.com.br. Acesso em maio de 2018.

AGÊNCIA NACIONAL DE VIGILÂNCIA SANITÁRIA - ANVISA. 2005. Disponível em www.anvisa.gov.br. Acesso em maio de 2018.

AGÊNCIA NACIONAL DE VIGILÂNCIA SANITÁRIA - ANVISA. 2010. Disponível em www.anvisa.gov.br. Acesso em maio de 2018.

AGÊNCIA NACIONAL DE VIGILÂNCIA SANITÁRIA - ANVISA. 2015. Disponível em www.anvisa.gov.br. Acesso em maio de 2018.

AGÊNCIA NACIONAL DE VIGILÂNCIA SANITÁRIA - ANVISA. 2018. Disponível em www.anvisa.gov.br. Acesso em maio de 2018.

AYRANCI, E.; TUNC, S. A. 2003. Method for the measurement of the oxygen permeability and the development of edible films to reduce the rate of oxidative reactions in fresh foods. Food Chemistry 80:423-431.

BESSA, A. T. M. 2016. Caracterização físico-química de alho comum e nobre em função do tempo de armazenamento. Dissertação de Mestrado da Universidade Federal Rural do Semi-árido, Mossoró, Rio Grande do Norte, RN. pp.45-60.

BESSA, A. T. M. et al. 2017. Caracterização físicoquímica de alho 'BRS Hozan' e 'Roxo Pérola de Caçador' em função do tempo de armazenamento. Revista Colombiana de Ciências Hortícolas 11:368-377.

BOTREL, D. A. et al. 2007. Qualidade de alho (Allium sativum) minimamente processado envolvido com revestimento comestível antimicrobiano. Ciência e Tecnologia de Alimentos 27:32-38.

BOTREL, N.; OLIVEIRA, V. R. 2012. Cultivares de cebola e alho para processamento. Horticultura Brasileira (Suplemento CD-ROM) 22:485-496.

BUSO, E. K. R. P. de M. et al. 2014. Comportamento pós colheita de mandioquinha-salsa revestida com quitosana. Revista Ciência Agronômica 45:850-855.
CAMILI, E. C. et al. 2007. Avaliação de quitosana, aplicada em pós-colheita, na proteção de uva'Itália' contra Botrytis cinerea. Summa Phytopathologica 215-221.

CHITARRA, M. I. F.; CHITARRA, A. B. 2005. Póscolheita e frutos e hortaliças: fisiologia e manuseio. Lavras, Universidade Federal de Lavras, ESAL/ FAEPE.

COMPANHIA NACIONAL DE ABASTECIMENTO - CONAB. 2018. Disponível em www. conab.gov.br. Acesso em abril de 2018.

COSTA, D. R. D. 2018. Resíduo industrial de aveia: extração e caracterização do amido visando aplicação em revestimento comestível adicionado de composto antifúngico natural. Tese de Mestrado. Universidade Tecnológica Federal do Paraná, UFPR, PR. 32-54p.

COSTA, T. L. E. et al. 2012. Avaliação de coberturas comestíveis compostas por quitosana e argila no revestimento em tomates sob refrigeração pelo método dipping. Revista Verde de Agroecologia e Desenvolvimento Sustentável 7:12-13.

DE ARAÚJO, V. R.; SHIRAI, M. A. 2017. Aplicação de revestimento comestível de quitosana em Brócolis minimamente processado. Boletim do Centro de Pesquisa de Processamento de Alimento 34:23-23.

DE CARVAlHO, V. D. et al. 1991. Tempo de armazenamento e qualidade do alho, cv. Amarante. Pesquisa Agropecuária Brasileira 26:1679-1684.

DE MEDEIROS, E. K. R. P. et al. 2014. Comportamento pós-colheita de mandioquinhasalsa revestida com quitosana. Revista Ciência Agronômica 45:850-855.

DURANGO, A. M.; SOARES, N. F. F.; ANDRADE, N. J. 2006. Microbiological evaluation of an edible antimicrobial coating on minimally processed carrots. Food control 17:336-341.

EMPRESA BRASILEIRA DE PESQUISA A G R O P E C U Á R I A - E M B R A P A / HORTALIÇAS. 2018. Disponível em www.embrapa.br. Acesso em janeiro de 2018. 
FAI, A. E. C.; STAMFORD, T. C. M.; STAMFORD, T. L. M. 2008. Potencial biotecnológico de quitosana em sistemas de conservação de alimentos. Revista Iberoamericana de Polímeros. 9:435-451.

FÉLIX, D. T. et al. 2018. Dose de quitosana para aplicação pré-colheita em uva cv. Sweet Globe®: resultados preliminares. In: Jornada de Integração da Pós-Graduação da Embrapa Semiárido, Petrolina. Anais. Embrapa Semiárido, Petrolina, PE. pp.23-43.

GRANJA, R. D. C. B.; DA CUNHA, M. D. G. C. 2018. Avaliação do Efeito do Revestimento a Base de Quitosana na Conservação Pós-Colheita do Umbu. In:Congresso de Iniciação Científica (CONIC), 22. Universidade Federal do Amazonas, UFAM, AM. pp.12-44.

GUIMARÃES SANCHES, A. et al. 2018. Preservação da Qualidade Pós-Colheita da Carambola Comsolução Filmogênica de Quitosana. In Colloquium Agrariae 14:15-32.

HENRIQUE, C. M.; CEREDA, M. P.; SARMENTO, S. B. S. 2008. Características físicas de filmes biodegradáveis produzidos a partir de amidos modificados de mandioca. Ciência e Tecnologia de Alimentos 28:231-240.

INSTITUTO ADOLFO LUTZ - IAL. 2018. Secretaria da Saúde - Governo do Estado de São Paulo. Disponível em www.ial.sp.gov.br. Acesso em janeiro de 2018.

JORGE, P. C. S. et al. 2011. Maga Royal Gala revestida com quitosana estocada a temperatura ambiente. Boletim do Centro de Pesquisa e Processamento de Alimentos 29:253-2011.

LIMA, D. M. et al. 2006. Tabela brasileira de composição de alimentos: versão II. NEPA/ UNICAMP, Campinas, SP.

LOPES, W. D. A. R. et al. 2016. Grangeiro, L. C. Caracterização físico-química de bulbos de alho submetido a períodos de vernalização e épocas de plantio. Horticultura Brasileira 34:20-26.

LOREVICE, M. V.; MOURA, M. R. D.; MATTOSO, L. H. 2014. Nanocompósito de polpa de mamão e nanopartículas de quitosana para aplicação em embalagens. Química Nova 1:931-936.

MELO, F. D. S. N. D. 2015. Qualidade de goiaba "paluma" minimamente processada sob recobrimentos a base de quitosana, cloreto de cálcio e alginato. Dissertação Mestrado. Universidade Federal da Paraíba, UFPB, Paraíba, PB. 23p.

NASSER, F. A. D. C. M. et al. 2016. Conservação de mangabas submetidas à aplicação de quitosana. Científica 44:279-285.

OFFICIAL METHODS OF ANALYSIS - AOAC. 1970. Disponível em www.aoac.org. Acesso em maio de 2018.

OFFICIAL METHODS OF ANALYSIS - AOAC. 1990. Disponível em www.aoac.org. Acesso em abril de 2018.

OFFICIAL METHODS OF ANALYSIS - AOAC. 2000. Disponível em www.aoac.org. Acesso em janeiro de 2018.

OFFICIAL METHODS OF ANALYSIS - AOAC. 2011. Disponível em www.aoac.org. Acesso em maio de 2018.

PRATI, P. et al. 2010. Alterações físico-químicas em pastas de alho. Revista Iberoamericana de Tecnología Postcosecha 11:21-30.

QIU, M. et al. 2013. Effect of chitosan coating on postharvest green asparagus quality. Carbohydrate Polymers 92:2027-2032.

SANTOS, C. A. A. et al. 2008. Uso de quitosana e embalagem plástica na conservação pós-colheita de pêssegos' Douradão'. Revista Brasileira de Fruticultura 30:88-93.

SCHWIMMER, S; WESTON, W. J. 1961. Enzymatic development of pyruvic acid in onion as a measure of pungency. Journal of Agricultural and Food Chemistry 9:303-304.

SILVA, P. S. et al. 2017. Avaliação de coberturas comestíveis compostas por fécula de mandioca e quitosana no revestimento em laranjas sob armazenamento refrigerado. Revista da Jornada de Pós-Graduação e Pesquisa-congrega, ICES 3:766-774. 
SOUZA, M. L. D. et al. 2011. Pós-colheita de mangas' Tommy Atkins' recobertas com quitosana. Revista Brasileira de Fruticultura 5:337-343.

TAVARES, R. et al. 2017. Avaliação da cera de carnaúba (Copernicia prunifera) como revestimento de mandioquinha-salsa (Arracacia xanthorrhiza Bancroft.). Global Science and Technology 9:20-27. 